\title{
High Resolution Mass Spectrometry for the Recognition and Structural Characterization of a New Antimicrobial Compound
}

\author{
Lùcia Carrano ${ }^{1}$, Annamaria Naggi ${ }^{2}$, Elena Urso ${ }^{2 *}$ \\ ${ }^{1}$ Fondazione Istituto Insubrico Ricerca per la Vita, Gerenzano, Italy \\ ${ }^{2}$ Istituto di Ricerche Chimiche e Biochimiche G. Ronzoni, Milan, Italy \\ Email: *urso@ronzoni.it
}

How to cite this paper: Carrano, L., Naggi, A. and Urso, E. (2018) High Resolution Mass Spectrometry for the Recognition and Structural Characterization of a New Antimicrobial Compound. Pharmacology \& Pharmacy, 9, 135-148.

https://doi.org/10.4236/pp.2018.95011

Received: April 7, 2018

Accepted: May 20, 2018

Published: May 23, 2018

Copyright $\odot 2018$ by authors and Scientific Research Publishing Inc. This work is licensed under the Creative Commons Attribution International License (CC BY 4.0).

http://creativecommons.org/licenses/by/4.0/

\begin{abstract}
Identification of novel specialized metabolites or bioactive compounds represents the main objective in the research field of natural product leads and drug discovery. Mass spectrometry (MS) provides a central tool to expedite and make more efficient the discovery and isolation phases, while minimizing the waste of resources on rediscovery of known compounds. MS contributes acutely to elucidation and identification of numerous species because it allows molecular mass and structural features determination. In particular, identification of the elemental composition of a precursor ion of interest by accurate mass measurement and investigation of dissociative processes undergone by the molecule, represent a worthy methodology to access the structure assignment. The aim of this study was to discover and identify novel antibacterial drugs from microbial source in a jungle of already known compounds. The focus of this paper is on the analytical strategy that permitted the disclosure of a new compound, otherwise confused with other substances. Emphasis is placed on the interpretation of the ESI-MS/MS fragmentation pattern that combined with high resolution mass determination, allowed step by step to properly deduce the exact molecular formula of an unknown component with a molecular weight higher than 1500 Daltons.
\end{abstract}

\section{Keywords}

Antibiotic Development, Antibiotic Discovery, High Resolution Mass Spectrometry, Molecular Formula, MS/MS Fragmentation, FT ICR MS

\section{Introduction}

Antibiotic-resistant bacterial strains are a major health challenge and medical 
need, as for example, illustrated by the recent emergence and spread of Klebsiella pneumoniae strains resistant to carbapenems or multidrug-resistant (MDR) Staphylococcus aureus strains. Organizations such as the US Centers for Disease Control and Prevention (CDC), the European Centre for Disease Prevention and Control (ECDC) and the World Health Organization (WHO) are considering these infections an emergent global disease and a major public health problem; new strategies are described to combat them [1] [2]. Contrary to the common belief that the exposure to antibiotics is confined to the modern antibiotic era, numerous researches have shown that traces of antibiotics were found in ancient people [3] [4] [5]. Undoubtedly, the accumulation of antibiotic resistance genes in human populations showing their roots in the past and a continuous development in the future, represents a huge challenge [6] [7] [8] [9].

Mortality due to multidrug-resistant bacterial infections and relative economic costs to treat them are surprisingly high. The initial strategy, involving the modification of existing antimicrobials to improve their effectiveness, showed that novel resistance mechanisms were developed by the bacteria and often resulted in a strong failure. So, considering that the prevention of antibiotic resistance remains presently the best care, the discovery and development of newer and more efficient antibiotics is a continuous and essential process. Most antibiotics still in use as therapeutics are natural products (NP), and were identified through screenings of microorganisms, mostly soil bacteria; ninety five percent of the antibiotics described to date originate from leads discovered by screening NP extracts or fractions [10] [11]. So, even though it was registered a strong decline of interest in NP screening bacterial, fungal, plant, and marine source, it still represents a reservoir of new molecules [10] [12]. One of the most critical issue of NP screening is the rediscovery of known compound since this approach is activity driven, so for example it results critical rapidly distinguish between new chemical entities and novel activities of know molecules. This compound identification process is named as dereplication by activity or structure, sometimes also indicated as deconvolution or novelty identification [10] [12] [14]. Recent dramatic improvement in analytical, genomic, metabolomic and informatic techniques together with the use of high throughput and/or "high content screening" give new impulse to NP-based drug discovery program, claiming the possibility to dereplicate compounds from microbes directly in the strain culture without any purification [12] [13] [14] [15]. MS techniques, plus pro and con, used to identify new molecules using a "structure-based approach" or a bioactivity-driven approach are reviewed in 2016 by Henke and Kelleher [16]. With the advent of soft ionization sources, in the middle of $80 \mathrm{~s}$, the mass spectrometry became highly suited for the analysis of high polarity, thermolabile and high molecular weight compounds by detecting intact precursor ions with low or no fragmentation. Furthermore, with the capability of the direct coupling to liquid chromatography, mass spectrometry has proved to be a very useful technique for procedures of random screening of compounds, particularly when other tech- 
niques failed [17]-[22]. Concerning the high-resolution, in the last 40 years mass spectrometers have evolved through many stages to become commonly available tools that using accurate mass and high resolution capabilities allow to provide great specificity and obtain more comprehensive information. Among these technological advancements also endowed with extremely high sensitivity, mass spectrometry has always shown his essential role by greatly contributing to detection and identification of unknown species [16] [23]. Anyhow, metabolite identification remains a bottleneck also in mass spectrometry (MS)-based metabolomics. Currently, this process relies heavily on tandem mass spectrometry (MS/MS) spectra generated separately for peaks of interest identified from previous MS runs [24]. In this study, we show how relatively simple analysis of combined LC-MS and UV profiles of active microbial fraction extract can ensure novelty determination by matching these data against those stored in a database of known microbial compounds. ESI full scan and tandem mass spectra have been measured to describe their fragmentation behavior. Although FT instruments provide mass accuracies in the $0.5-1 \mathrm{ppm}$ range, the number of possible elemental compositions for a given ion rises as the molecular weight increases. However, this work shows an effective example of how CID experiments, combined with the information derived from theoretical calculations, allowed to arrive at the definitive sum formula assignment.

\section{Material and Methods}

\subsection{Chemicals and Reagents}

Methanol (LC-MS grade) was purchased from Sigma-Aldrich. Unless otherwise noted, reagents and solvents are used as received from commercial suppliers.

\subsection{Sample Preparation}

Briefly, the broth surnatant was adsorbed on Diaion Hp20 resin and eluted with $70 \%$ di $\mathrm{CH}_{3} \mathrm{OH}$. The active extract $(110 \mathrm{mg}$ ) was fractionated by bioassay guided methods using HPLC-MS-DAD on reversed-phase C18-column [25] [26]. The chromatographic separation was performed on a reverse phase C18(2) Luna semipreparative column $(250 \times 10 \mathrm{~mm}, 10 \mu \mathrm{m}$ particle size, Phenomenex $)$. A binary solvent system was used for gradient elution at $4 \mathrm{~mL} / \mathrm{min}$ and at room temperature of solvent $\mathrm{A}(10 \mathrm{mM}$ ammonium formate $\mathrm{pH} 4.5)$ and solvent $\mathrm{B}$ $\left(\mathrm{CH}_{3} \mathrm{CN}\right)$ with a multistep program: $10 \% \mathrm{~B}$ for $4 \mathrm{~min}, 35 \% \mathrm{~B}$ at $\min 36,90 \% \mathrm{~B}$ at $\min 38,90 \%$ B for $5 \mathrm{~min}$, then returned to $10 \% \mathrm{~B}$ for equilibrating the chromatographic column.

The active sample (data not shown) is eluted at $21 \mathrm{~min}$. About $2 \mathrm{mg}$ of enriched compound were obtained.

\subsection{LC-MS Analysis}

The collected sample fraction was then submitted to HPLC-DAD-MS analysis on a HPLC system Accela Instrument (Thermo Fisher Scientific, San Jose, CA) 
coupled to LTQ-xl ion trap mass spectrometer (Thermo Fisher Scientific, San Jose, CA).

Chromatographic separation was performed using a Luna C18(2) $(250 \times 4.6$ $\mathrm{mm}, 5 \mu \mathrm{m}$ particle size, Phenomenex) at a flow rate of $1 \mathrm{~mL} / \mathrm{min}$, using $10 \mathrm{mM}$ ammonium formate $\mathrm{pH} 4.5$ as solvent $\mathrm{A}$ and $\mathrm{CH}_{3} \mathrm{CN}$ as solvent Baccording to the gradient: $10 \% \mathrm{~B}$ for $4 \mathrm{~min}, 35 \% \mathrm{~B}$ at $\min 36,90 \% \mathrm{~B}$ at $\min 38,90 \% \mathrm{~B}$ for 5 $\mathrm{min}, 10 \% \mathrm{~B}$ for equilibrating the chromatographic column. The effluent from the column is splitted into a 5:95 ratio and the majority $(\sim 950 \mu \mathrm{L} / \mathrm{min})$ is diverted to PDA detector to acquire the complete full UV-visible spectrum in the range $200-600 \mathrm{~nm}$ (the UV detection was followed at $223 \mathrm{~nm}$ ), while the remaining 50 $\mu \mathrm{L} / \mathrm{min}$ are diverted to the electrospray ionization (ESI) interface of the ion trap mass spectrometer.

The mass detector was previously tuned and calibrated by infusion at 5 $\mu \mathrm{L} / \mathrm{min}$ of the Pierce LTQ ESI Positive ion calibration solution. MS conditions are: positive polarity, spray voltage $2.7 \mathrm{kV}$; capillary temperature $275^{\circ} \mathrm{C}$; capillary voltage $4.5 \mathrm{~V}$.

\subsection{HRMS Measurements}

Full scans and fragmentation high resolution mass spectra were recorded on 7.0 T Fourier transform ion cyclotron resonance (FTICR) instrument equipped with electrospray (ESI) source (Solarix, Bruker Daltonics). The sample solution prepared at very low concentration (about $2 \mathrm{pmol} / \mu \mathrm{L}$ in water: methanol 1:1 (v/v)) was run by direct infusion to source at $4 \mu \mathrm{l} / \mathrm{min}$. The electrospray interface was set in positive ionization mode (Spray Voltage $-3200 \mathrm{~V}$ ), to record total ion current profiles in the m/z 200 - 3000 mass range. Nitrogen was used as a drying (3.7 liters/min) and nebulizing gas (1.0 bar) and the ion transfer capillary was kept at $180^{\circ} \mathrm{C}$.

Mass calibration was performed by using sodium trifluoroacetate solution $(0.05 \mathrm{mg} / \mathrm{mL}$ in water-acetonitrile $1: 1 \mathrm{v} / \mathrm{v})$.

MS/MS fragmentation experiments were produced by collision induced fragmentation (CID) at different collision energies.

\section{Results and Discussion}

The HPLC-MS-DAD data show that the active compound has a molecular weight (MW) of 1571 Daltons (Da) and has two absorbance maxima at 227 and $277 \mathrm{~nm}$ (Figure 1). The lack of peculiar chromophore renders dereplication studies based almost exclusively on MSanalysis, but resolution and mass accuracy provided by an ion trap mass spectrometer is insufficient to make any hypothesis. The full scan spectrum of the sample solution, recorded by the high resolution and high accuracy ESI-FT ICR mass spectrometer, mainly shows a doubly and a triply charged ion with monoisotopic mass at $\mathrm{m} / \mathrm{z} 786.3977(\mathrm{z}+2)$ and $\mathrm{m} / \mathrm{z} 524.6007(\mathrm{z}+3)$, respectively, allowing to calculate the molecular mass of the main component that corresponds to 1570.8 Daltons (Figure 2). 


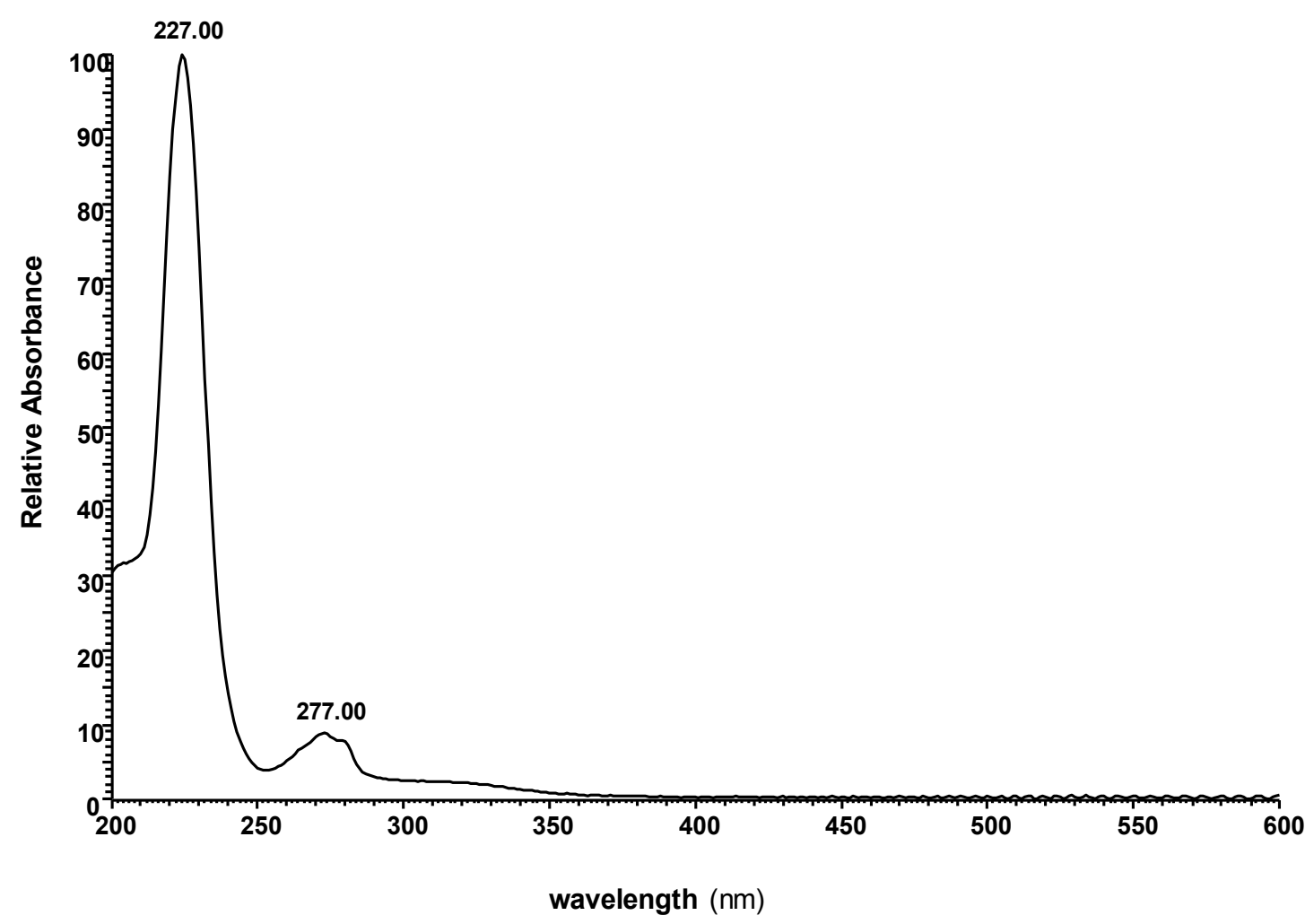

Figure 1. UV-visible spectrum recorded with a PDA-HPLC apparatus.

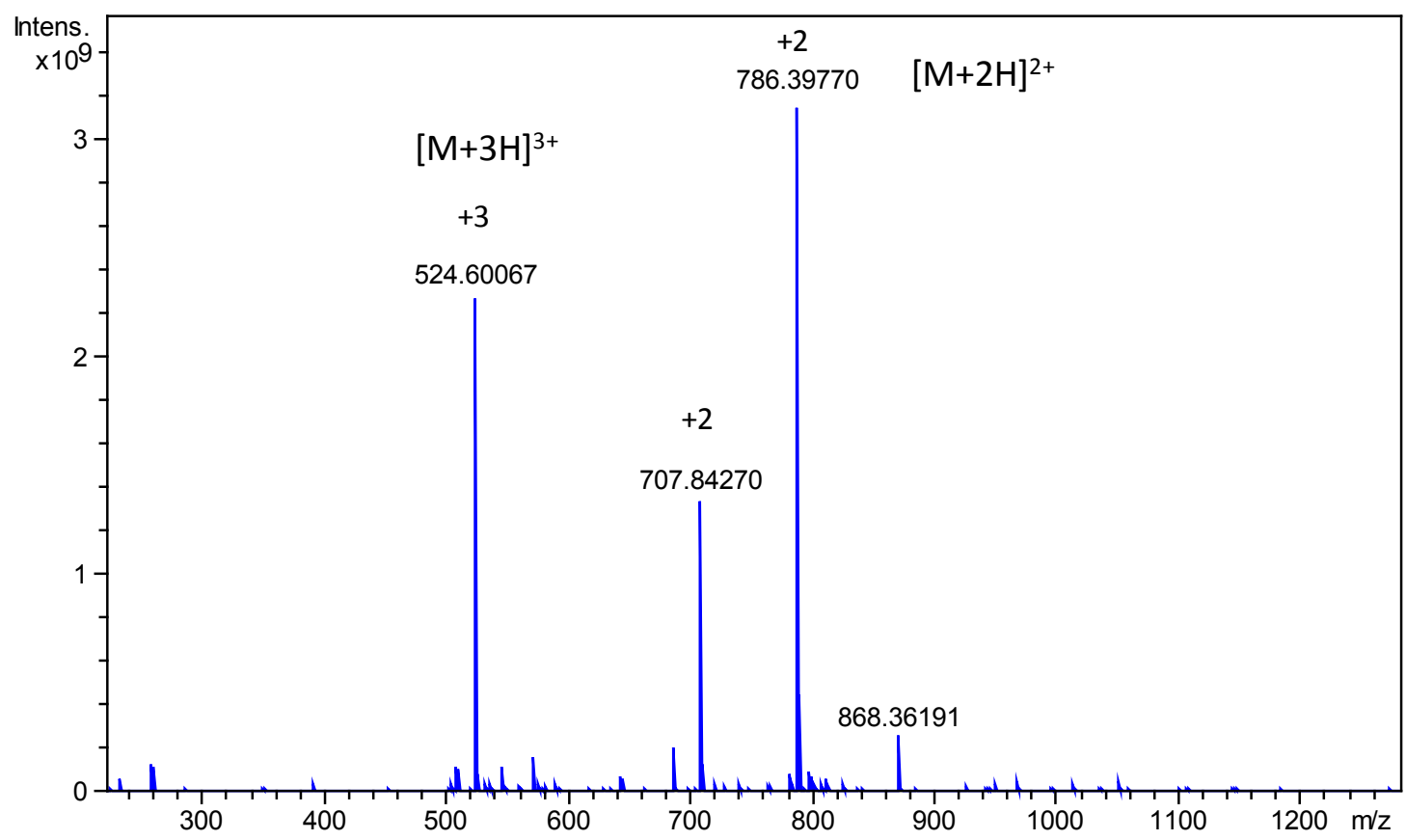

Figure 2. Full scan mass spectrum recorded by an ESI-FT ICR MS system.

Even with the excellent mass accuracy provided by this type of analytical instrument, numerous molecular formulas have been found consistent with the experimental mass signals, owing to the high molecular weight. In this case, the 
structural information arising from fragmentation experiments can be of considerable help leading to the identification of the exact sum formula.

Both doubly and triply charged ions were isolated and fragmented by collision induced dissociation (CID). Different collision energies were tested to find the best conditions for the generation of fragment-rich mass spectra. MS/MS ions populations spectra of the doubly-protonated parent ion at $\mathrm{m} / \mathrm{z} 786.4$ were compared in Figure 3. The collision amplitude of $12 \mathrm{~V}$ was chosen (Figure 4) as the precursor ion is not completely depleted and ion fragments were produced with mass values ranging from $\mathrm{m} / \mathrm{z} \sim 1400$ to $\mathrm{m} / \mathrm{z} \sim 550$ Daltons. As shown in Figure 5, we found that the same collision energy appeared the best fragmentation condition of the triply charged parent ion and resulted in the formation of ions from $\mathrm{m} / \mathrm{z} \sim 1100$ to $\mathrm{m} / \mathrm{z} \sim 300$ Daltons, increasing the structural coverage.

Here we reported the attempts to combine very accurate mass measurements and structural information arising from the fragmentation experiments. Starting from the parent ion at $\mathrm{m} / \mathrm{z} 786.4(\mathrm{z}+2)$, consecutive losses were recorded showing interesting mass differences ( $\Delta$, in Daltons): 43.9898, 157.1103, 130.0630 and 143.0946, respectively. The high accuracy measurements allowed to calculate the corresponding molecular formulas $\left(\mathrm{CO}_{2}, \mathrm{C}_{8} \mathrm{H}_{15} \mathrm{~N}_{1} \mathrm{O}_{2}, \mathrm{C}_{6} \mathrm{H}_{10} \mathrm{O}_{3}\right.$

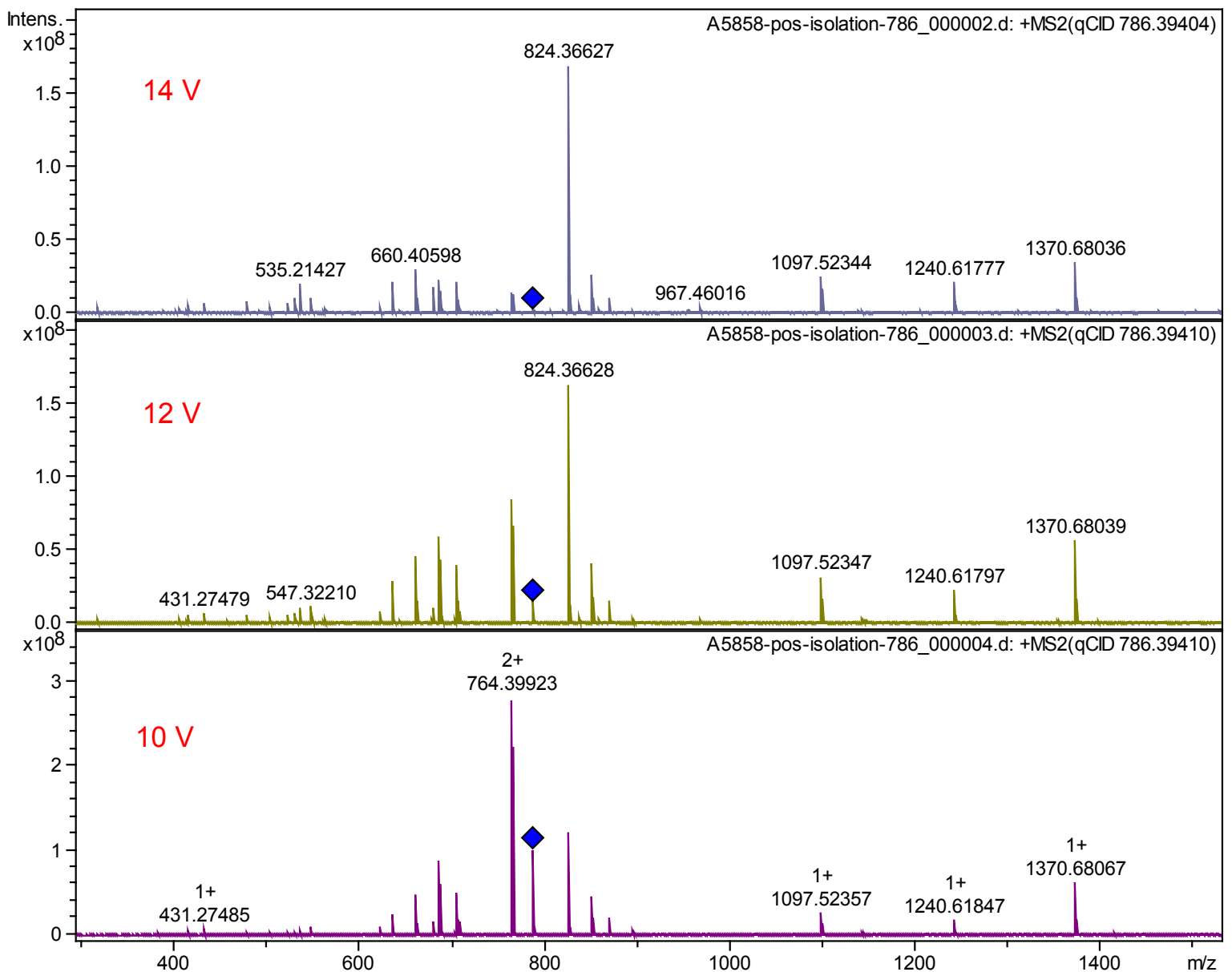

Figure 3. MS/MS fragmentation experiments of $\mathrm{m} / \mathrm{z} 786.0$ recorded at different collision energies. 

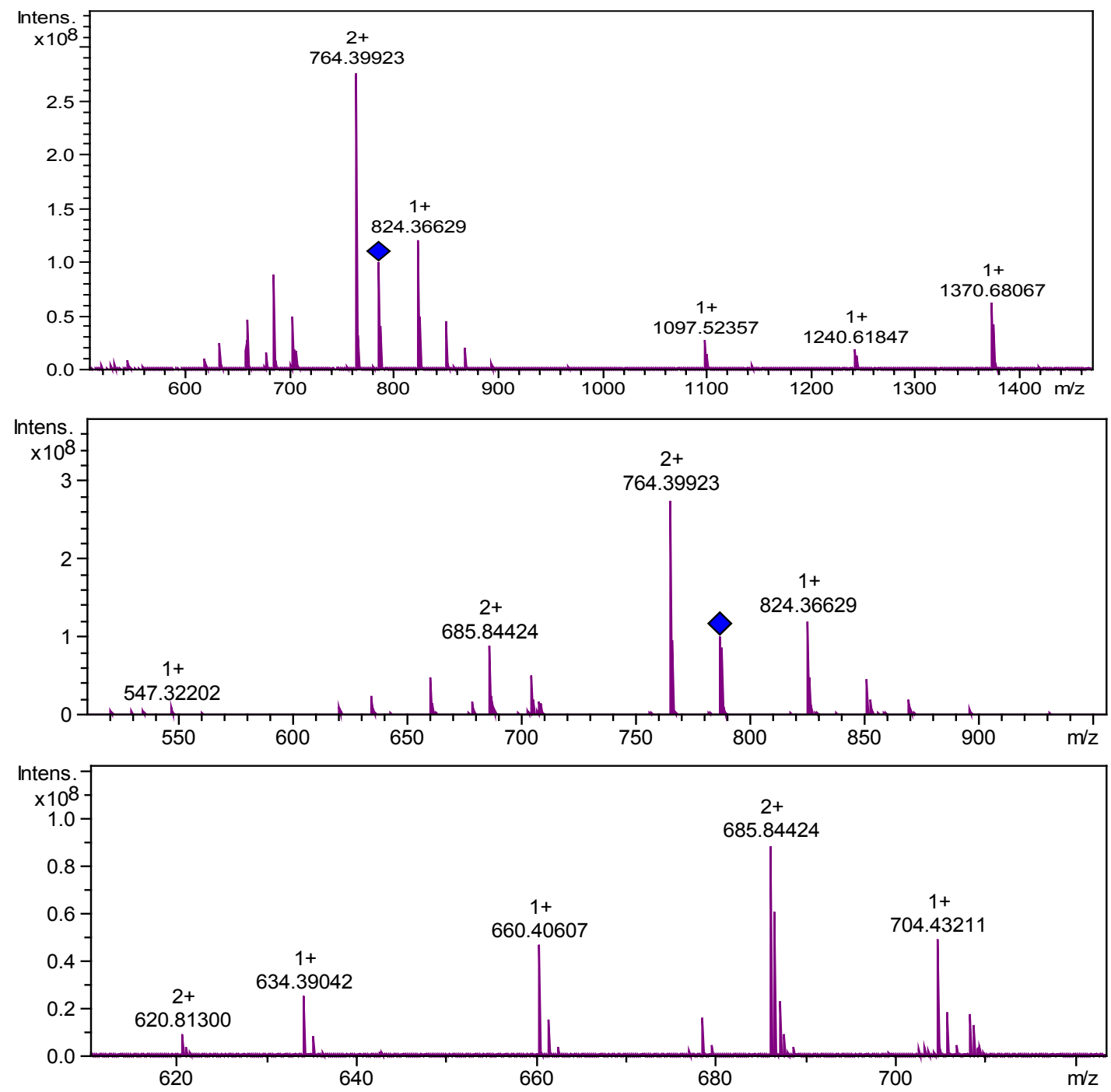

Figure 4. MS/MS fragmentation spectrum of doubly charged ion parent at $\mathrm{m} / \mathrm{z} 786.0$ (optimized collision energy at $12 \mathrm{~V}$ ): 1) the whole spectrum (upper panel); 2) expanded portion from $\mathrm{m} / \mathrm{z} 500$ to $\mathrm{m} / \mathrm{z} 1000 ; 3$ ) expanded portion from $\mathrm{m} / \mathrm{z} 600$ to $\mathrm{m} / \mathrm{z} 720$.

and $\mathrm{C}_{7} \mathrm{H}_{13} \mathrm{~N}_{1} \mathrm{O}_{2}$, respectively). Its fragmentation behavior suggested the presence of a labile carboxylic acid functional group and the junction of three pieces.

Fragmentation of the triply charged ion parent at $\mathrm{m} / \mathrm{z} 524.6$ (Figure 5) allowed to obtain additional ion fragments from m/z 1097.5 to $\mathrm{m} / \mathrm{z} 274.2$ and reveals consecutive neutral losses of 130.0630 (m/z 967.5), 143.0946 (m/z 824.4), $146.0579(\mathrm{~m} / \mathrm{z} 678.3), 143.0946(\mathrm{~m} / \mathrm{z} 535.2)$, in a similar way to the first portion of the molecule. An additional mass shift of 146.0579 was detected and we found that the sum formula $\mathrm{C}_{6} \mathrm{H}_{10} \mathrm{O}_{4}$ can fit it with high mass accuracy. Finally, the in-depth investigation of the lower fragments agrees with a molecule portion at $\mathrm{m} / \mathrm{z} 535.2$ that produces the signal at $\mathrm{m} / \mathrm{z} 491.2$ by releasing $\mathrm{CO}_{2}$ and then is broken to produce the signal at $\mathrm{m} / \mathrm{z}$ 290.2. The precursor and almost all fragmentation ions were listed in Table 1 , in which each experimental $\mathrm{m} / \mathrm{z}$ ion is described by a proposed molecular formula and its theoretical mass. Combining 


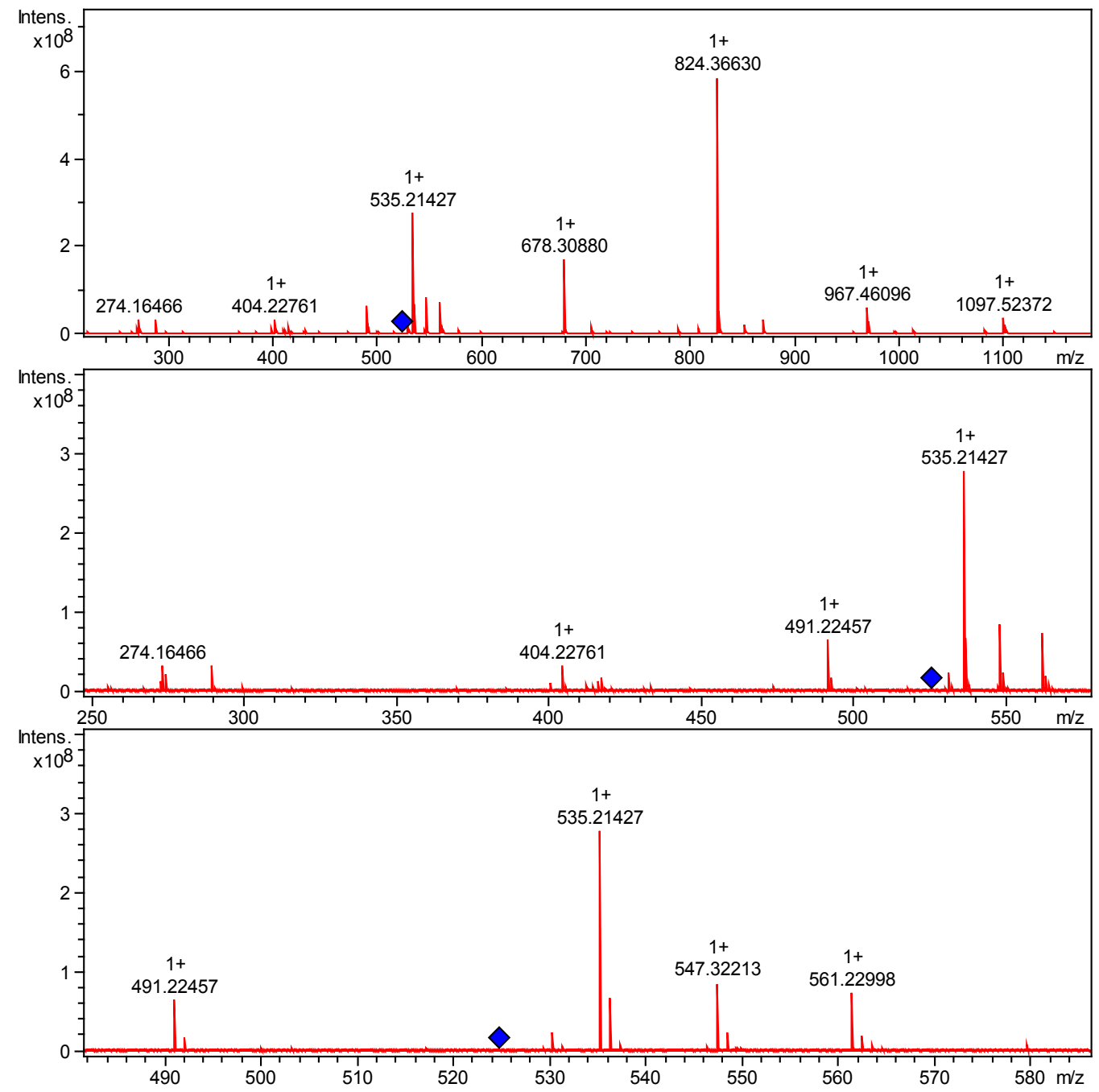

Figure 5. MS/MS fragmentation spectrum of triply charged ion parent at $\mathrm{m} / \mathrm{z} 524.6$ (optimized collision energy at $12 \mathrm{~V}$ ): 1) The whole spectrum (upper panel); 2) Expanded portion from $\mathrm{m} / \mathrm{z} 250$ to $\mathrm{m} / \mathrm{z} 600 ; 3$ ) Expanded portion from $\mathrm{m} / \mathrm{z} 480$ to $\mathrm{m} / \mathrm{z} 590$.

step by step each sum formula determined for each fragment allowed to calculate the whole molecular formula of the parent ion $\left(\mathrm{C}_{70} \mathrm{H}_{118} \mathrm{~N}_{6} \mathrm{O}_{33}\right)$. This sum formula exhibits an error of $1.4 \mathrm{ppm}$ between experimental and theoretical mass signals and shows a good overlap of isotopic patterns distribution (Figure 6).

Measurement at high resolution and high mass accuracy allowed to exclude some well-known antibiotics having very close molecular weight, as depicted in Figure 7 and Figure 8 for Orienticin d and Evernomicin b1, respectively. In particular, the isotopic profile of the compound did not show the typical pattern due to chlorine presence further confirming that the molecule cannot be Everninomycin.

Extremely high mass-accuracy measurements and fragmentation patterns (Table 1) compared to information provided by Kersten [15] [23] data (Table 2 ), allowed to propose a molecule containing at least seven condensed sugar units: three neutral losses of 143.0946, two neutral losses of 130.0630, one neutral 
Table 1. Molecular formulas assignment of the main fragmentation species.

\begin{tabular}{|c|c|c|c|c|c|c|}
\hline Experimental $\mathrm{m} / \mathrm{z}$ & $(\mathrm{z})$ & $\Delta,(\mathrm{Da})$ & $\begin{array}{l}\text { Mass difference } \\
\text { attribution }\end{array}$ & $\begin{array}{l}\text { The whole molecular } \\
\text { formula proposed }\end{array}$ & Theoretical m/z & Error (ppm) \\
\hline 274.1647 & +1 & - & - & $\begin{array}{c}\mathrm{C}_{13} \mathrm{H}_{23} \mathrm{~N}_{1} \mathrm{O}_{5} \\
\mathrm{C} 13 \mathrm{H} 23 \mathrm{~N} 1 \mathrm{O} 5\end{array}$ & 274.1649 & 0.7 \\
\hline 290.1595 & +1 & 15.9948 & $\mathrm{O}_{1}$ & $\mathrm{C}_{13} \mathrm{H}_{23} \mathrm{~N}_{1} \mathrm{O}_{6}$ & 290.1598 & 1.0 \\
\hline 404.2276 & +1 & 114.0681 & $\mathrm{C}_{6} \mathrm{H}_{10} \mathrm{O}_{2}$ & $\mathrm{C}_{19} \mathrm{H}_{33} \mathrm{~N}_{1} \mathrm{O}_{8}$ & 404.2279 & 0.7 \\
\hline 491.2246 & +1 & 86.9970 & $\mathrm{C}_{2} \mathrm{H}_{1} \mathrm{~N}_{1} \mathrm{O}_{3}$ & $\mathrm{C}_{21} \mathrm{H}_{34} \mathrm{~N}_{2} \mathrm{O}_{11}$ & 491.2235 & 2.2 \\
\hline 535.2143 & +1 & 43.9897 & $\mathrm{CO}_{2}$ & $\mathrm{C}_{22} \mathrm{H}_{34} \mathrm{~N}_{2} \mathrm{O}_{13}$ & 535.2134 & 1.7 \\
\hline 579.2041 & +1 & 43.9897 & $\mathrm{CO}_{2}$ & $\mathrm{C}_{23} \mathrm{H}_{34} \mathrm{~N}_{2} \mathrm{O}_{15}$ & 579.2032 & 1.6 \\
\hline 678.3088 & +1 & 143.0946 & $\mathrm{C}_{7} \mathrm{H}_{13} \mathrm{~N}_{1} \mathrm{O}_{2}$ & $\mathrm{C}_{29} \mathrm{H}_{47} \mathrm{~N}_{3} \mathrm{O}_{15}$ & 678.3080 & 1.2 \\
\hline 824.3663 & +1 & 146.0579 & $\mathrm{C}_{6} \mathrm{H}_{10} \mathrm{O}_{4}$ & $\mathrm{C}_{35} \mathrm{H}_{57} \mathrm{~N}_{3} \mathrm{O}_{19}$ & 824.3659 & 0.5 \\
\hline 967.4610 & +1 & 143.0946 & $\mathrm{C}_{7} \mathrm{H}_{13} \mathrm{~N}_{1} \mathrm{O}_{2}$ & $\mathrm{C}_{42} \mathrm{H}_{70} \mathrm{~N}_{4} \mathrm{O}_{21}$ & 967.4605 & 0.5 \\
\hline 1097.5237 & +1 & 130.0630 & $\mathrm{C}_{6} \mathrm{H}_{10} \mathrm{O}_{3}$ & $\mathrm{C}_{48} \mathrm{H}_{80} \mathrm{~N}_{4} \mathrm{O}_{24}$ & 1097.5235 & 0.2 \\
\hline 1240.6178 & +1 & 143.0946 & $\mathrm{C}_{7} \mathrm{H}_{13} \mathrm{~N}_{1} \mathrm{O}_{2}$ & $\mathrm{C}_{55} \mathrm{H}_{93} \mathrm{~N}_{5} \mathrm{O}_{26}$ & 1240.6182 & 0.3 \\
\hline $\begin{array}{c}1370.6804 \\
685.8442\end{array}$ & $\begin{array}{l}+1 \\
+2\end{array}$ & 130.0630 & $\mathrm{C}_{6} \mathrm{H}_{10} \mathrm{O}_{3}$ & $\mathrm{C}_{61} \mathrm{H}_{103} \mathrm{~N}_{5} \mathrm{O}_{29}$ & $\begin{array}{c}1370.6811 \\
685.8442\end{array}$ & $\begin{array}{l}0.5 \\
<0.1\end{array}$ \\
\hline 764.3992 & +2 & 157.1103 & $\mathrm{C}_{8} \mathrm{H}_{15} \mathrm{~N}_{1} \mathrm{O}_{2}$ & $\mathrm{C}_{69} \mathrm{H}_{118} \mathrm{~N}_{6} \mathrm{O}_{31}$ & 764.3993 & 1.3 \\
\hline 786.3954 & +2 & 43.9898 & $\mathrm{CO}_{2}$ & $\mathrm{C}_{70} \mathrm{H}_{118} \mathrm{~N}_{6} \mathrm{O}_{33}$ & 786.3943 & 1.4 \\
\hline
\end{tabular}

Table 2. Identification of sugar units according to Kersten [15].

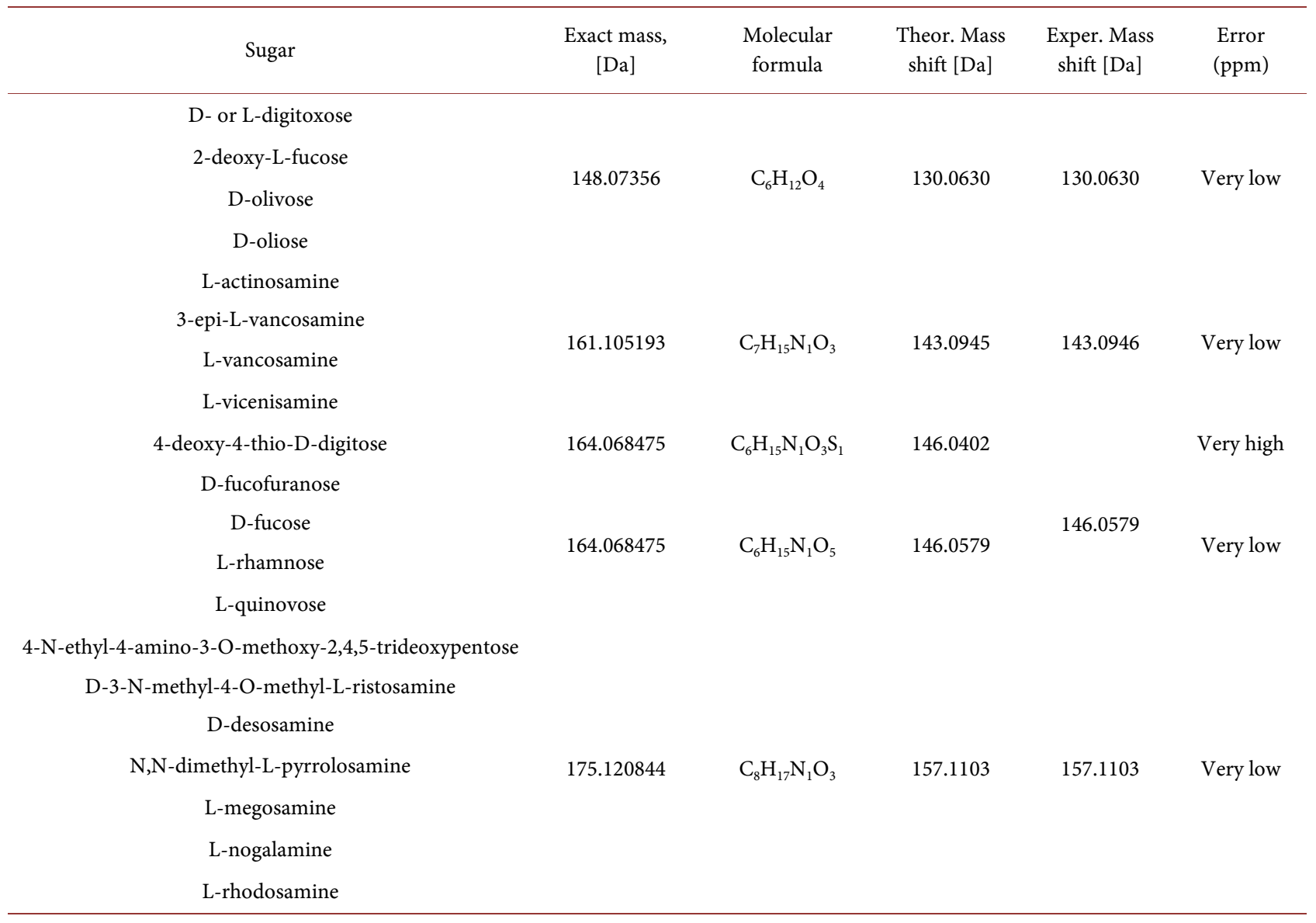




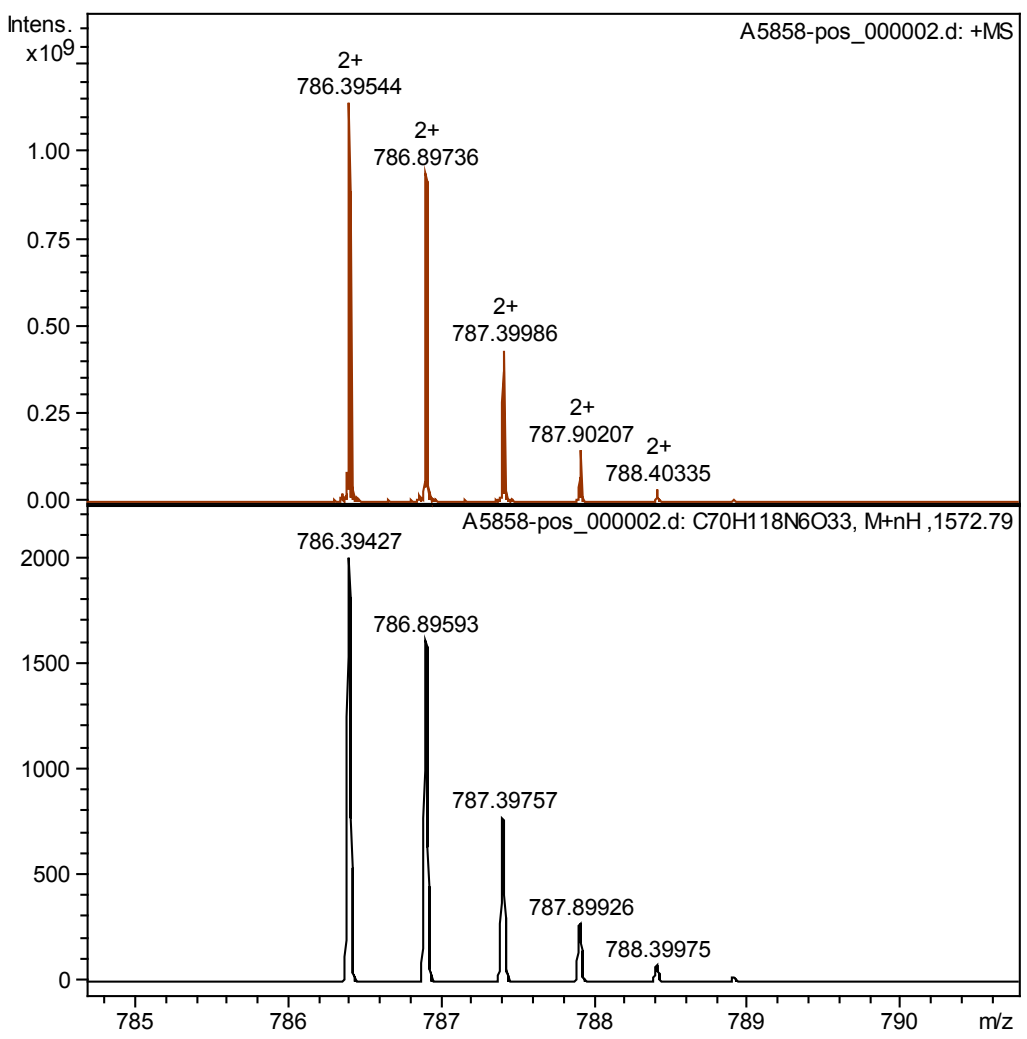

Figure 6. Sum formula $\mathrm{C}_{70} \mathrm{H}_{118} \mathrm{~N}_{6} \mathrm{O}_{33}$ : comparison between theoretical and experimental isotopic patterns of doubly protonated ions.

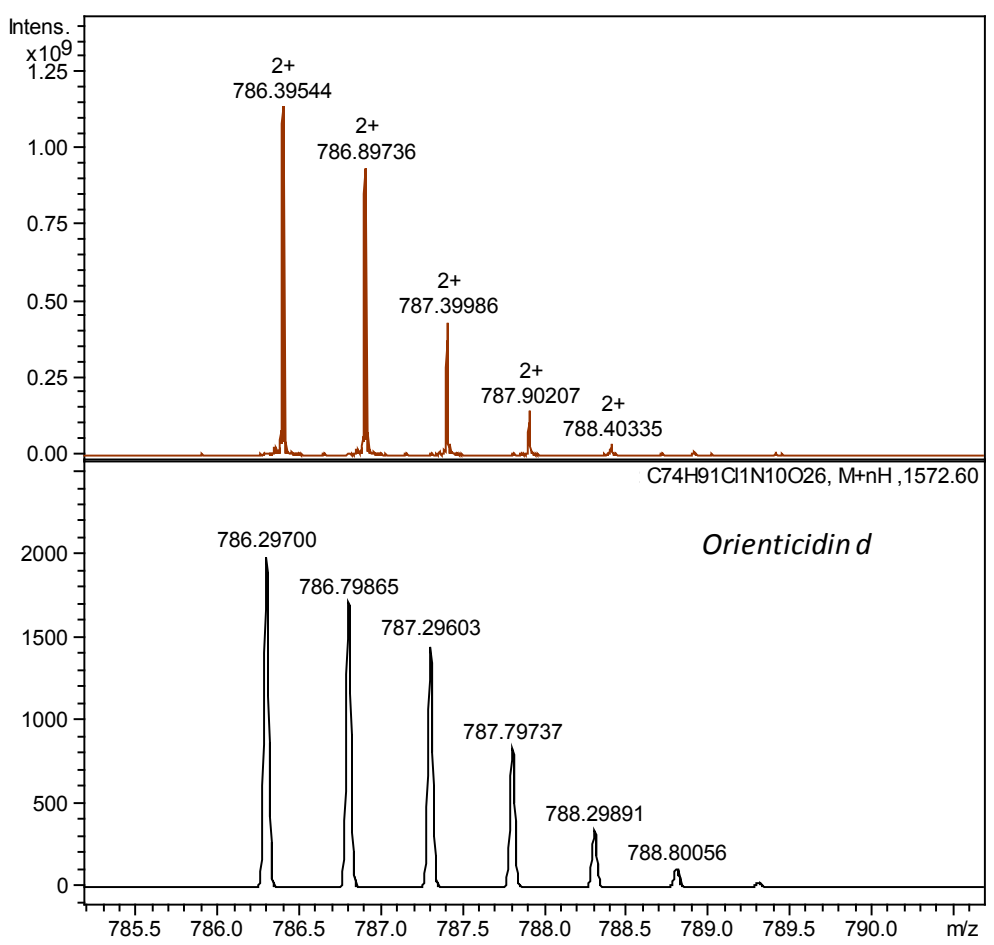

Figure 7. Comparison of mass values and isotopic patterns: 1) experimental $\mathrm{m} / \mathrm{z}$; 2) theoretical $\mathrm{m} / \mathrm{z}$ corresponding to the sum formula of Orienticidin $\mathrm{d}$ antibiotic $\left(\mathrm{C}_{70} \mathrm{H}_{118} \mathrm{~N}_{6} \mathrm{O}_{33}\right)$. 


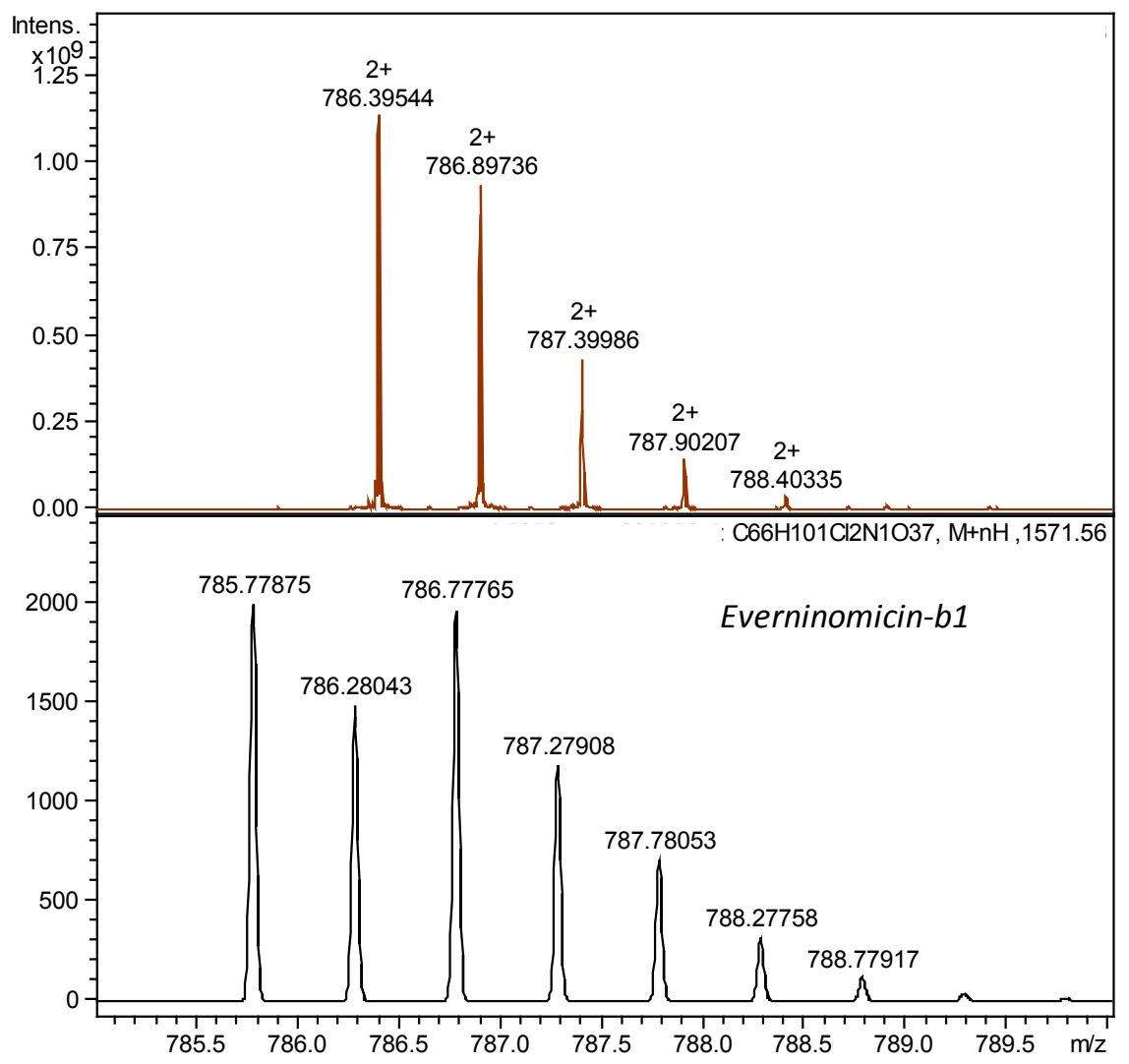

Figure 8. Comparison of mass values and isotopic patterns: 1) experimental $\mathrm{m} / \mathrm{z} ; 2$ ) theoretical $\mathrm{m} / \mathrm{z}$ corresponding to the sum formula of Everninomicin-b1 antibiotic $\left(\mathrm{C}_{66} \mathrm{H}_{101} \mathrm{Cl}_{2} \mathrm{~N}_{1} \mathrm{O}_{37}\right)$.

loss of 146.0579 and another one of 157.1103, generated in the fragmentation experiments and attributed to glycosidic residues. Particularly, four different types of sugars were found, two of them corresponding to amino sugars. The error between theoretical and experimental mass values is always very low $(<1$ $\mathrm{ppm}$ ) and allowed to reject the hypothesis of 4-deoxy-4-thio-D-digitose sugar.

Because of a high number of different molecules can fit the same molecular formula, further investigation by NMR technique will be required to obtain the exact structure.

More efforts were performed in the elucidation of the last portion of the molecule; our hypothesis agrees with a nitro phenolic ring (supported by a neutral loss of $201 \mathrm{Dafrom} \mathrm{m} / \mathrm{z} 491.2$ to $\mathrm{m} / \mathrm{z} 290.2)$ that undergoes a further fragmentation by releasing nitro ethenone $\left(\mathrm{C}_{2} \mathrm{HNO}_{3}\right)$.

\section{Concluding Remarks}

The present work was successful in identifying a new antimicrobial compound by means of high resolution mass spectrometry, without the contribution from other analytical strategies. Great attention was dedicated to structural characterization aspects that allowed to calculate step by step the molecular formula of the active component of interest contained in the microbial culture of a soil bac- 
terium extract belonging to the FIIRV proprietary strain library. Activity data, being outside the scope of this work, will be presented elsewhere.

These data resulted essential to distinguish the compound among already identified species and confirm its novelty. The potential of high-resolution tandem mass spectrometry to discover new components without resorting to complementary techniques is worthy to be highlighted. Fast and low-consuming sample characteristics make it a very useful technique in the initial step of antimicrobials screening speeding dereplication and novelty identification.

This work shows also that using structural information available in public database and without the help of sophisticated software, it is possible to perform accurate structural comparison and obtain clear indication of novelty. Moreover, our data suggest that mining soil bacteria can still be a valid strategy for the discovery of molecules with interesting biological activity.

\section{Acknowledgements}

The authors are grateful to FIIRV (Fondazione Istituto Insubrico Ricerca per la Vita) for providing the compound produced by a microbial soil strain culture belonging to their library.

\section{References}

[1] Bal, A.M., David, M.Z., Garau, J., Gottlie, T., Mazzei, T., Scaglione, F., Tatteving, P. and Gould, I.M. (2017) Future Trends in the Treatment of Methicillin-Resistant Staphylococcus aureus (MRSA) Infection: An In-Depth Review of Newer Antibiotics Active Against an Enduring Pathogen. Journal of Global Antimicrobial Resistance, 10, 295-303. https://doi.org/10.1016/j.jgar.2017.05.019

[2] David, M.Z., Dryden, M., Gottlieb, T., Tattevind, P. and Goulde, M. (2017) Recently Approved Antibacterials for Methicillin-Resistant Staphylococcus aureus (MRSA) and Other Gram-Positive Pathogens: The Shock of the New. International Journal of Antimicrobial Agents, 50, 303-307. https://doi.org/10.1016/j.ijantimicag.2017.05.006

[3] Bassett, E.J., Keith, M.S., Armelagos, G.J., Martin, D.L. and Villanueva, A.R. (1980) Tetracycline-Labeled Human Bone from Ancient Sudanese Nubia (A.D.350). Science, 209, 1532-1534. https://doi.org/10.1126/science.7001623

[4] Nelson, M.L., Dinardo, A., Hochberg, J. and Armelagos, G.J. (2010) Brief Communication: Mass Spectroscopic Characterization of Tetracycline in the Skeletal Remains of an Ancient Population from Sudanese Nubia 350-550 CE. American Journal of Physical Anthropology, 143, 151-154. https://doi.org/10.1002/ajpa.21340

[5] Cook, M., Molto, E. and Anderson, C. (1989) Fluorochrome Labelling in Roman Period Skeletons from Dakhleh Oasis, Egypt. American Journal of Physical Anthropology, 80, 137-143. https://doi.org/10.1002/ajpa.1330800202

[6] Fair, R.J. and Tor, Y. (2014) Antibiotics and Bacterial Resistance in the 21st Century. Perspectives in Medicinal Chemistry, 6, 25-64. https://doi.org/10.4137/PMC.S14459

[7] McArthur, A.G., Waglechner, N., Nizam, F., Yan, A., Azad, M.A., Baylay, A.J., Bhullar, K., Canova, M.J., De Pascale, G., Ejim, L., Kalan, L., King, A.M., Koteva, K., Morar, M., Mulvey, M.R., O’Brien, J.S., Pawlowski, A.C., Piddock, L.J., Sutherland, 
A.D., Tang, I., Taylor, P.L., Thaker, M., Wang, W., Yan, M., Yu, T. and Wright, G.D. (2013) The Comprehensive Antibiotic Resistance Database. Antimicrobial Agents and Chemotherapy, 57, 3348-3357. https://doi.org/10.1128/AAC.00419-13

[8] Peterson, L.R. (2009) Bad Bugs, No Drugs: No ESCAPE Revisited. Clinical Infectious Diseases, 49, 992-993. https://doi.org/10.1086/605539

[9] Boucher, H.W., Talbot, G.H., Bradley, J.S., Edwards, J.E., Gilbert, D., Rice, L.B., Scheld, M., Spellberg, B. and Bartlett, J. (2009) Bad Bugs, No Drugs: No ESKAPE! An Update from the Infectious Diseases Society of America. Clinical Infectious Diseases, 48, 1-12. https://doi.org/10.1086/595011

[10] Brown, E.D. and Wright, G.D. (2016) Antibacterial Drug Discovery in the Resistance era. Nature, 529, 336-343. https://doi.org/10.1038/nature17042

[11] Newman, D.J. and Cragg, G.M. (2016) Natural Products as Sources of New Drugs from 1981 to 2014. Journal of Natural Products, 79, 629-661. https://doi.org/10.1021/acs.jnatprod.5b01055

[12] Newman D. (2017) Screening and Identification of Novel Biologically Active Natural Compounds 1000 Research, 6 (F1000FacultyRev), 783.

[13] Esquenazi, E., Yang, Y.-L., Watrous, J., Gerwick, W.H. and Dorrestein, P.C. (2009) Imaging mass Spectrometry of Natural Products. Natural Product Reports, 26, 1521-1534. https://doi.org/10.1039/b915674g

[14] Carrano, L. and Marinelli, F. (2015) The Relevance of Chemical Dereplication in Natural Product Screening. Journal of Applied Bioanalysis, 1, 55-67.

https://doi.org/10.17145/jab.15.010

[15] Kersten, R.D., Ziemert, N., Gonzalez, D.J., Duggan, B.M., Nizet, V., Dorrestein, P.C. and Moore, B.S. (2013) Glycogenomics as a Mass Spectrometry-Guided Genome-Mining Method for Microbial Glycosylated Molecules. Proceedings of the National Academy of Sciences of the United States of America, 110, E4407-E4416. https://doi.org/10.1073/pnas.1315492110

[16] Henke, M.T. and Kelleher, N.H. (2016) Modern Mass Spectrometry for Synthetic Biology and Structure-Based Discovery of Natural Products. Natural Product Reports, 33, 942-950. https://doi.org/10.1039/C6NP00024J

[17] Fenn, J.B., Mann, M., Meng, C.K., Wong, S.F. and Whitehouse, C.M. (1989) Electrospray Ionization for Mass Spectrometry of Large Biomolecules. Science, 246, 64. https://doi.org/10.1126/science.2675315

[18] Loo, J.A., Quinn, J.P., Ryu, S.I., Henry, K.D., Senko, M.W. and McLafferty, F.W. (1992) High-Resolution Tandem Mass Spectrometry of Large Biomolecules. Proceedings of the National Academy of Sciences, 89, 286-289. https://doi.org/10.1073/pnas.89.1.286

[19] Ganem, B., Li, Y.-T. and Henion, J.D. (1991) Detection of Noncovalent Receptor-Ligand Complexes by Mass Spectrometry. Journal of the American Chemical Society, 113, 6294-6296. https://doi.org/10.1021/ja00016a069

[20] Gelpi, E. (2008) From Large Analogical Instruments to Small Digital Black Boxes: 40 Years of Progress in Mass Spectrometry and Its Role in Proteomics. Part I 1965-1984. Journal of Mass Spectrometry, 43, 419-435. https://doi.org/10.1002/jms.1403

[21] Korfmacher, W.A. (2005) Using Mass Spectrometry for Drug Metabolism Studies. CRC Press, Boca Raton, 1-34.

[22] Caprioli, R.M., Malorni, A. and Sindona, G. (1997) Selected Topics in Mass Spectrometry in the Biomolecular Sciences. Nato Science Series C: Mathematical and 
Physical Sciences, Vol. 504. https://doi.org/10.1007/978-94-011-5165-8

[23] Kersten, R.D., Yang, Y.L., Xu, Y., Cimermancic, P., Nam, S.J., Fenical, W., Fischbach, M.A., Moore, B.S. and Dorrestein, P.C. (2011) A Mass Spectrometry-Guided Genome Mining Approach for Natural Product Peptidogenomics. Nature Chemical Biology, 7, 794-802. https://doi.org/10.1038/nchembio.684

[24] Lynn, K., Cheng, M.-L., Chen, Y.-R., Hsu, C., Chen, A., Lih, T.M., Chang, H.-Y., Huang, C., Shiao, M.-S., Pan, W.-H., Sung, T.-Y. and Hsu, W.-L (2015) Metabolite Identification for Mass Spectrometry-Based Metabolomics Using Multiple Types of Correlated Ion Information. Analytical Chemistry, 87, 2143-2151. https://doi.org/10.1021/ac503325c

[25] Castiglione, F., Lazzarini, A., Carrano, L., Corti, E., Ciciliato, I., Gastaldo, L., Candiani, P., Losi, D., Marinelli, F., Selva, E. and Parenti, F. (2008) Determining the Structure and Mode of Action of Microbisporicin, a Potent Lantibiotic Active against Multiresistant Pathogens. Chemistry \& Biology, 15, 22-31.

https://doi.org/10.1016/j.chembiol.2007.11.009

[26] Carrano, L., Abbondi, M., Turconi, P., Candiani, G. and Marinelli, F. (2015) A Novel Microbisporicin Producer Identified by Early Dereplication during Lantibiotic Screening. BioMed Research International, 2015, Article ID: 419383. https://doi.org/10.1155/2015/419383 